\title{
Ser Jovem e Ser Aluno: entre a escola e o Facebook
}

\author{
Cirlene Cristina de Sousa' \\ Geraldo Magela Pereira Leão' \\ 'Universidade Federal de Minas Gerais (UFMG), Belo Horizonte/MG - Brasil
}

RESUMO - Ser Jovem e Ser Aluno: entre a escola e o Facebook. Este artigo discute os resultados de uma pesquisa qualitativa que abordou o tema da relação entre juventude e midiatização da cultura contemporânea com jovens estudantes em três turmas do ensino médio. Os dados foram coletados por meio da observação participante e da aplicação de 333 questionários, 28 entrevistas e três grupos de discussão. Partiu-se do pressuposto de que a avalanche de tecnologias que se misturam à vida das pessoas, em geral, tem uma singular afetação no que tange à vida juvenil. Os resultados indicaram que jovens pesquisados vivenciavam conexões midiáticas amplas e heterogêneas, permeando seus tempos e espaços, vínculos afetivos e comunicacionais e experiências escolares de diferentes formas segundo a situação juvenil em observação.

Palavras-chave: Jovens. Ensino Médio. Redes Sociais.

ABSTRACT - Being Young and Being a Student: between the school and the Facebook. This article discusses the results of a qualitative research on the relationship between youth and mediatization in the contemporary culture with three groups of secondary education students. Data was collected by means of participatory observation and 333 questionnaires, 28 interviews and three discussion groups. It started with the assumption that the huge amount of technologies that are blended to people's lives, in general, has a singular effect on the youth life. The results indicated that the youth experienced extensive and heterogeneous mediatic connections, pervading their time and space, their affective and communicative links, and their school experiences in several ways, according to the situation observed. Keywords: Youth. Secondary Education. Social Networks.

Educação \& Realidade, Porto Alegre, v. 41, n. 1, p. 279-302, jan./mar. 2016. 279 http://dx.doi.org/10.1590/2175-623655761 


\section{Introdução}

Este artigo discute os resultados de uma pesquisa (Sousa, 2014) que abordou o tema da relação entre juventude e midiatização da cultura contemporânea a partir das experiências de estudantes de duas escolas do ensino médio nas redes sociais. Partiu-se do pressuposto de que as tecnologias da informação fazem parte do cotidiano desses jovens, envolvendo processos de socialização e de construção de suas subjetividades. Buscou-se investigar, a partir da observação de suas experiências escolares e de seus depoimentos, como eles compreendiam a presença das tecnologias em seus cotidianos escolares e não escolares. Assim, o interesse da pesquisa se voltou para a análise da inter-relação entre ser jovem e ser aluno, a partir da experiência dos sujeitos (percepção do tempo, identidade, aprendizagem, sociabilidade, etc.) no contexto de midiatização da cultura contemporânea.

Neste artigo, em específico, apresentamos parte dos seus resultados referentes à afetação ${ }^{1}$ da cultura midiatizada na condição de alunos dos jovens pesquisados, a partir da imbricação feita por eles entre a sala de aula off-line e a sala de aula on-line. Inicialmente, aborda-se o contexto e o recorte metodológico que orientou a coleta e a análise dos dados. Depois, uma primeira parte na qual se discute sobre o processo de midiatização da cultura contemporânea. Em seguida, o artigo aborda as afetações dessa cultura midiatizada nos modos de ser jovem-aluno hoje. Por fim, destaca-se o encontro dessa dupla ser jovem e ser aluno nas turmas virtuais inscritas por esses alunos no ambiente do Facebook.

A problematização da relação entre juventude e o processo de midiatização da cultura contemporânea e sua afetação na vida escolar dos jovens pesquisados fundamentou-se em abordagens sociológicas complementares como a Sociologia do Indivíduo (Martucelli, 2012), a Sociologia da Experiência (Dubet, 1994) e a Sociologia Reflexiva (Melucci, 2005). Focadas na observação dos hábitos, vínculos e sentidos manifestados pelos sujeitos em suas ações individuais e coletivas, estas abordagens se distinguem das perspectivas sociológicas clássicas por destacar as experiências dos sujeitos como ações formadoras dos processos sociais, superando leituras sociológicas funcionalistas e estruturalistas que, a partir de diferentes perspectivas, preconizam uma relação muitas vezes direta e linear entre indivíduo e estrutura social.

Nas perspectivas sociológicas que fundamentam a análise, busca-se compreender os fenômenos sociais a partir da ação dos sujeitos e suas experiências. Em outros termos, trata-se de perspectivas sociológicas que buscam dar conta das experiências sociais vividas pelos indivíduos, salientando "[...] os limites de uma sociologia tradicional que busca apreender o indivíduo com base numa certa representação do mundo social" a partir da qual "[...] a significação e a trajetória das ações dos indivíduos [são] deduzidas de sua posição e função em um domí- 
nio social constituído" e "[...] os sujeitos, por sua vez, seriam percebidos como produtos imediatos de um entrelaçamento de forças de origem social" (Sposito; Setton, 2013, p. 249). Estes sociólogos contemporâneos abandonam formas teóricas universais e se focam na realidade empírica, espacial e temporal singulares, segundo vivências históricas particulares que permitam "[...] compreender os mecanismos responsáveis pela fabricação de indivíduos em contextos variados" (Sposito; Setton, 2013, p. 250).

A perspectiva sociológica de Melucci (2004) influenciou de forma singular a pesquisa, ao considerar os jovens atores-chave para se compreender as transformações sociais recentes, com seus desdobramentos em termos de educação, cultura, comunicação, vínculos e normas sociais. As análises do autor recaem, especialmente, na constatação das mudanças profundas, hoje em curso, quanto aos processos de socialização e individuação juvenil. Por um lado, aos sujeitos contemporâneos, sobretudo aos jovens, abrem-se novos campos de possibilidades “[...] de redefinição e invenção das capacidades 'formais' de aprendizado, habilidades cognitivas, criatividade"; sendo que "[...] os indivíduos percebem a possibilidade de estender, potencializar e orientar significativamente suas ações" (Melucci, 2004, p. 66). Por outro lado, ainda segundo o autor, os sujeitos se defrontam com os limites de suas escolhas, pois tais possibilidades quase sempre lhes escapam, "[...] uma vez que sofrem uma regulação capilar de suas capacidades de ação, que afeta suas raízes motivacionais e suas formas de comunicação" (Melucci, 2004, p. 66).

Essa perspectiva adotada privilegiou ainda a pesquisa qualitativa para a inteligibilidade do objeto abordado. Conforme André (2008), as pesquisas que se baseiam em abordagens qualitativas se fundamentam numa perspectiva de valorização do papel ativo dos sujeitos em todo e qualquer processo de produção do conhecimento e tem por pressuposto que a realidade é sempre uma construção social. Segundo a autora, para tal abordagem, "[...] o mundo dos sujeitos, os significados que atribuem às suas experiências cotidianas, sua linguagem, suas produções culturais e suas formas de interações sociais constituem os núcleos centrais de preocupação dos pesquisadores" (André, 2008, p. 47).

O referencial teórico adotado, conjugado à dimensão compreensiva e interpretativa da pesquisa qualitativa, conduziu a coleta de dados, partindo de questões como: Que elementos do processo de midiatização da cultura contemporânea se manifestavam na experiência cotidiana dos jovens alunos? Como o processo de midiatização participava das sociabilidades e processos de socialização dos mesmos jovens? Como os dispositivos midiáticos afetavam as práticas e/ou os modos de ser aluno? O que esses jovens-alunos midiatizados diziam de si e da escola?

Do amplo campo da metodologia qualitativa, optou-se pelo estudo de caso. Essa escolha se justificou pelo escopo de compreender as questões de pesquisa a partir da vivência midiático-escolar de três 
turmas de jovens estudantes do ensino médio, observadas on-line e off-line. Para tanto, foram selecionadas duas escolas: uma da rede pública de ensino, Escola Estadual Francisca Amaral; e outra da rede particular, Instituto Carmem Pereira ${ }^{2}$.

O Instituto particular Carmem Pereira mantém as modalidades de Educação Infantil, Ensino Fundamental I e II, Ensino Médio, a EJA e um trabalho específico de Educação e valorização da Melhor Idade. À comunidade e aos alunos são oferecidos também cursos como Escolinha de Esporte, com futsal, vôlei, basquete, balé e capoeira; aulas de flauta doce; coral; catequese; teatro; oficinas de Origami, inglês e espanhol em parceria com a escola de línguas Number One. Inspirado em sua identidade católica, o Instituto Carmem Pereira dá singularidade para o seu projeto educacional ao inscrever como valores pregados pela instituição as relações interpessoais, a solidariedade, a vida e a justiça. A sua missão educativa maior é a formação de "[...] cidadãos autônomos, críticos, participativos, conscientes e competentes na busca de uma sociedade mais justa" (Instituto Carmem Pereira, 2011, p. 22). A escola se propõe a garantir a qualidade do ensino, que deve se construir conjugada com atitudes e valores cristãos, a fim de que se formem pessoas solidárias, críticas e éticas, capazes de enfrentar desafios.

Na escola pública Francisco do Amaral, são organizadas as modalidades de Ensino Fundamental I e II, e de Ensino Médio. A proposta pedagógica da instituição tem seus princípios educacionais norteados pela LDBEN (Brasil, 1996). O Projeto Político Pedagógico diz que a finalidade da escola é promover uma educação que vise ao pleno desenvolvimento do educando, em suas dimensões física, psicológica, moral, social e espiritual. Tal desenvolvimento deveria se expressar "[...] na crescente compreensão da realidade, no exercício da liberdade responsável, na convivência, na prática das relações democráticas, no serviço à sociedade e na abertura ao transcendente" (Escola Estadual Francisco do Amaral, 2011, p. 16).

Para a pesquisa de campo, foram selecionadas três turmas do segundo ano do ensino médio dessas escolas, envolvendo um total de 129 jovens-alunos, que foram acompanhados e entrevistados durante todo o ano letivo de 2012. Optou-se em pesquisar as turmas do segundo ano, tendo em vista que poderiam representar de maneira mais significativa as experiências mais recorrentes entre os alunos, sem as singularidades próprias do ano inicial e final dessa etapa da educação básica.

Os estudos de caso se procederam a partir de diferentes fontes (documentos, alunos, gestores e docentes) e instrumentos de coleta de dados (observação participante, questionários e entrevistas). A pesquisa de campo foi dividida em três fases. Na primeira fase, sistematizou-se a caracterização dos jovens-alunos das escolas pesquisadas. Buscou-se compreender como tais características se apresentavam em conexão com o processo de midiatização da cultura contemporânea. Para tanto, acompanhou-se o movimento dos alunos na chegada à escola e na 
ocupação dos espaços escolares. Foram utilizados instrumentos como questionários e observação participante. Por meio da aplicação de um questionário, colheram-se dados gerais de todos os jovens das séries do ensino médio das duas escolas pesquisas. O questionário foi composto por 34 questões, divididas em quatro blocos, abarcando informações pessoais, condições familiares, práticas culturais/sociabilidade e informações sobre o uso das mídias ${ }^{3}$. Por meio da observação participante de aulas e outras atividades relativas ao cotidiano escolar, buscou-se apreender as relações e posturas dos sujeitos envolvidos, a movimentação dos alunos pela escola, com atenção para as interações dos jovens entre si e com os demais sujeitos escolares na tentativa de captar suas reações, posturas e manifestações durante o cotidiano escolar. Para tanto, trabalhou-se com a observação das turmas aqui denominadas Avenida $2 \mathrm{~m} 1$ e $2 \mathrm{~m} 2$ do Instituto Carmem Pereira e a turma $2 \mathrm{H}$ da Escola Estadual Francisca do Amaral ${ }^{4}$.

Na segunda fase, foram realizadas entrevistas individuais e três grupos de discussão com os estudantes, além da análise de documentos das instituições, com o objetivo de aprofundar os dados reunidos pelos questionários e pela observação de campo. Nesse momento, o objetivo principal foi construir um mapeamento mais aprofundado da relação dos jovens com as diferentes mídias e compreender como essa vivência afetava seus discursos sobre o ser aluno e suas experiências escolares.

Nessa fase da pesquisa, participaram da entrevista 28 jovens das três turmas definidas para a observação, sendo 14 alunos da escola particular e 14 da escola pública. Os entrevistados foram selecionados a partir dos seguintes critérios: jovens com diferentes perfis no uso de mídias, jovens com diferentes posturas como alunos, e sexo, buscando um equilíbrio entre rapazes e moças, classe social e pertencimento étnico-racial. Todas as participações foram voluntárias e permitidas pelos pais.

Nos três grupos de discussão (dois realizados na escola particular e um na escola pública), houve a participação de 30 jovens. Cada grupo de discussão foi formado por 10 alunos. Tal atividade foi realizada nos próprios espaços escolares devido à dificuldade para deslocar os participantes para outras localidades. Na escola particular, as entrevistas foram realizadas em uma sala da biblioteca e, na escola pública, no laboratório de informática. Todas as discussões foram realizadas no horário das aulas, após autorização das respectivas coordenações pedagógicas e dos docentes. Para as entrevistas individuais e grupos de discussão, utilizou-se roteiro com questões semiestruturadas.

Como dito anteriormente, os estudos de caso incluíram ainda a análise de documentos que complementaram as informações obtidas por outras fontes e forneceram base para triangulação de alguns dados. Para a pesquisa documental, foram colhidas informações sobre a concepção educacional das duas escolas a partir da leitura dos seus respectivos Projetos Políticos Pedagógicos e Regimentos Internos. Por meio 
dos projetos e regimentos, foram colhidas informações gerais sobre a política educacional de cada escola e possíveis tópicos de interação e/ ou conflito entre a proposta escolar e a sociedade contemporânea midiatizada.

Trabalhou-se ainda com materiais (textos, charges, mensagens, trechos de música, chats, grupo de estudos, fragmentos literários) postados na turma escolar do Facebook ${ }^{5}$ e nos perfis individuais dos alunos nesta mesma rede social. Por meio dessa ambiência virtual, buscaram-se informações que complementassem dúvidas importantes do material empírico colhido na observação e entrevistas. Todo o material registrado nas turmas escolares do Facebook (ano de 2012) e também colhido das páginas individuais (ano de 2012) foi considerado na análise.

Depois da coleta dos materiais, partiu-se para a terceira fase, que abarcou a sistematização dos dados reunidos. Para tanto, foram aplicados os procedimentos da Análise de conteúdo (AC) e da Análise de discurso $(\mathrm{AD})^{6}$. Os referenciais da AC possibilitaram colocar em evidência os assuntos e os temas mais recorrentes e significativos a partir da quantificação de itens, ocorrência de certas frases ou famílias de palavras.

$\mathrm{Na} A D$, o discurso é objeto de estudo, mas ele é também um conceito. Segundo Benveniste (1974), o conceito de discurso implica dois componentes, que são o enunciado e a enunciação. O enunciado corresponde à história contada, ao que é dito, logo a enunciação corresponde à maneira de contar a história, a forma de dizer. Enunciado e enunciação estabelecem uma relação de pressuposição recíproca: não existe enunciado sem enunciação e vice-versa. A enunciação é vista também como $o$ ato de enunciar, ato que instala um enunciador (aquele que fala) e um enunciatário (aquele para quem é enunciada a fala). Partindo desse ponto, a análise de discurso trabalha sobre a relação entre enunciado e enunciação, e sobre a construção das figuras do discurso: os sujeitos do enunciado e os sujeitos da enunciação. No caso dos discursos dos jovens, tratou-se de compreender de que forma eles traduziam suas experiências midiáticas como jovens e alunos na contemporaneidade. Além disso, buscou-se analisar como são posicionados esses discursos no interior da escola onde eles experimentam de forma mais concreta a condição de aluno. Esse foi um ponto fundamental da análise de discurso: compreender os diferentes posicionamentos dos sujeitos de discurso, analisando as diferentes enunciações, os diferentes modos pelos quais os jovens se posicionavam sobre questões e debates a eles propostos.

Por meio dessas perspectivas sociológicas/qualitativas, chegou-se aos jovens-alunos e suas experiências midiatizadas, compreendendo-os como sujeitos na sua dupla condição de jovens e alunos conectados, com tempo e espaços heterogêneos próprios de experiência social contemporânea, tomados como atores sociais singulares que se inserem em múltiplas relações midiatizadas. Quais temas, expectativas e questões emergiam nas interações presenciais e virtuais observadas? Quais dimensões do ser jovem-aluno eram expressas pelos sujeitos da 
pesquisa? Como as relações escolares e midiáticas se configuravam entre eles? Mais especificamente, quais elementos das falas, comportamentos e interações juvenis observados permitiam compreender de forma mais complexa a relação entre a vivência escolar e midiática dos jovens pesquisados?

\title{
O Processo de Midiatização da Cultura
}

Segundo Braga (2007), o processo de midiatização da cultura contemporânea é significativo tanto em termos de proporção e incidência ampliada em todos os relacionamentos humanos e sociais, como também por sua "[...] penetrabilidade processual que faz do midiático um processo interacional de referência crescente, mesmo nas comunicações interpessoais" (Braga, 2007, p. 142). Para tal autor:

\begin{abstract}
Processos de referência são os processos ditos como principais, dominantes, de tendência hegemônica, os demais processos interacionais (que não sejam considerados de referência) teriam este como parâmetro, se refeririam a ele como critérios de validade e definidores de lógicas centrais. Assim, dentro da lógica da midiatização, os processos sociais da mídia passam a incluir, a abranger os demais, que não desaparecem, mas se ajustam (Braga, 2007, p. 142).
\end{abstract}

Isso significa que a midiatização da cultura contemporânea implicaria em novas formas de organização, visibilidade e presença no mundo dos indivíduos e das instituições sociais, com novos modos de negociação e/ou estratégias entre essas instituições e seus indivíduos. Assim, a midiatização inauguraria, para tais instituições e sujeitos, uma nova ambiência, um novo padrão de condutas e comportamentos diferenciados, com alterações perceptivas e organizadoras da realidade social, configurando assim novas formas de interação social.

Nesse contexto midiatizado, a mídia, além de funcionar como conjunto de meios instrumentais com suas mensagens, passa cada vez mais à condição de produtora de sentidos sociais. Para além da inovação tecnológica das mídias, essas inovações atingem os sujeitos com suas identidades, conhecimentos e sociabilidades, ampliando as suas formas de contato e expressão, alterando a sua percepção do tempo e do espaço e incrementando o seu circuito de informações locais e globais.

Isso não configura, porém, um processo cego do ponto de vista humano. Como observa Castells (2008), as tecnologias de informação não orientam, por si só, as relações entre pessoas, os escopos das instituições e os rumos histórico-culturais da sociedade. Há sempre uma potência decisiva reservada às ações humanas. A partir dessa compreensão, o autor define as tecnologias como fator influente e participador, mas não como causa da mudança multidimensional da sociedade.

Na compreensão desse cenário e na escuta dos jovens, observamos sujeitos que vivem esta tensão de lugares e tempos, ritmos e papéis 
que interferem nos sentidos produzidos sobre suas experiências sociais e escolares. Ao mesmo tempo, notamos que as novas tecnologias têm fornecido não só instrumentos para isso, ao modo de uma máquina que apressa o tempo moderno, mas oferecem também uma ambiência em que esses sujeitos se distinguem, conectam-se e entram em conflito, num processo de referenciamento, de trocas intersubjetivas e de produção de vínculos sociais que podem ser mais amplos ou restritos dependendo do seu uso.

Este contexto relacional dos jovens com a ambiência midiática tem sido um desafio para a instituição escolar, posto que o aluno que a frequenta já é e se percebe como jovem midiatizado, gerando tensões nas suas relações com a escola de muitas maneiras, conforme suas experiências cotidianas.

\section{Jovem-Aluno em Midiatização}

Pertencer a uma faixa etária representa, para cada indivíduo, uma condição provisória e transitória, vivida em um processo dinâmico. Isso significa que os indivíduos não pertencem a grupos etários: eles os atravessam. Esse processo se faz de maneira diferenciada em cada sociedade, determinado, por um lado, pelas atitudes sociais e, por outro, pela visão que os jovens têm de si mesmos. Levi e Schmitt (1996) observam que este processo de atravessamento não se caracteriza de modo estável ou universal, distinguindo-se do que poderia ser uma simples passagem etária.

Desse modo, pensar o ser jovem implica em reconhecer a condição dos sujeitos aí imbricados, as questões e os conflitos intrínsecos aos seus âmbitos de relações sociais. Sendo assim, o conceito de juventude não pode remeter "[...] a qualquer homogeneização, mas, ao contrário, à pluralidade e às circunstâncias que marcam a vida juvenil, considerando a diversidade e as múltiplas possibilidades inerentes ao sentido de ser jovem" (Dayrell, 1999, p. 3). Neste artigo, optamos por trabalhar com a noção de condição juvenil por considerá-la mais adequada para expressar a diversidade de experiências e pertencimentos às juventudes contemporâneas. Conforme Dayrell (2007, p. 1109):

Do latim, conditio refere-se à maneira de ser, à situação de alguém perante a vida, perante a sociedade. Mas, também, se refere às circunstâncias necessárias para que se verifique essa maneira ou tal situação. Assim existe uma dupla dimensão presente quando falamos em condição juvenil. Refere-se ao modo como uma sociedade constitui e atribui significado a esse momento do ciclo da vida, no contexto de uma dimensão histórico-geracional, mas também à sua situação, ou seja, o modo como tal condição é vivida a partir dos diversos recortes referidos às diferenças sociais - classe, gênero, etnia etc. 
Assim, atentos à pluralidade inscrita na midiatização da condição juvenil contemporânea, buscamos compreender, de forma singular, o que os jovens com os quais dialogamos carregam de específico nos seus modos de ser jovem e ser aluno, tendo presente o processo de midiatização da cultura. Para Baccega (2002), os jovens se abrem de forma espantosa aos apelos da mídia, ao mesmo tempo em que tal abertura faz com que eles provoquem mudanças e façam emergir novos interesses no próprio ambiente midiático, alcançado pelos modos juvenis de ser, conviver e expressar-se.

Os jovens pesquisados declararam ter ligação direta e habitual com três tipos de dispositivos midiáticos: televisão, computador e aparelhos móveis (celulares, iphone, ipod, tablet e ipad). De acordo com os dados coletados, todos os alunos da escola particular e $88,2 \%$ da escola pública usavam habitualmente a internet. O acesso à TV de sinal fechado (por assinatura) era de $90 \%$ e $62 \%$ respectivamente. Esses jovens passavam entre 2 a 6 horas diárias assistindo TV. Quanto ao computador, todas as famílias dos estudantes da escola particular e $77 \%$ da escola pública tinham pelo menos um aparelho. Com relação ao uso da internet por banda larga, esses números eram 97\% e 69\% respectivamente. Com relação aos aparelhos móveis, sua presença era tão marcante, que apenas dois jovens declararam não fazer uso desse tipo de dispositivo.

Dos usos desses dispositivos, foram observados dois pontos importantes: a) Ao falarem dos dispositivos midiáticos, os jovens se referiram mais intensamente à dimensão das relações do que à dimensão técnica em si. Eles disseram usar os aparelhos digitais e o computador, sobretudo, para informações e relacionamentos. b) A maioria dos entrevistados demonstrou intimidade com a linguagem dos dispositivos midiáticos: os jovens falaram claramente de suas preferências por marcas e empresas, comentaram diferenças de gêneros televisivos, exploraram os vários tipos de aplicativos e funções dos aparelhos digitais; e disseram preferir aparelhos convergentes e televisão a cabo. Esses dispositivos incidiam com grande centralidade na percepção de si e de suas relações, como revelaram alguns depoimentos: "Eu e meu iphone temos uma história de amor" (Entrevista com Lorena, escola particular, 2012; "Meu iphone é tudo na minha vida" (Irene, escola pública, 2012). Podemos dizer que tratava-se de uma afetação de mão dupla entre a linguagem midiática e a linguagem cotidiana dos jovens, que se verificou na experiência dos jovens pesquisados, questão abordada a seguir.

\section{Desafio ao Tempo Linear da Escola}

Os jovens pesquisados, observados em suas ambiências relacionais escolares, desafiavam o tempo linear ali proposto ao dar continuidade às suas interações midiáticas: acessavam seus perfis do Facebook, enviavam mensagens para os colegas em sala, assistiam a vídeos, resolviam dúvidas de conteúdo das disciplinas e enviavam a matéria para colegas ausentes na sala de aula. Durante seu tempo escolar, esses

Educação \& Realidade, Porto Alegre, v. 41, n. 1, p. 279-302, jan./mar. 2016. 
jovens manipulavam seus aparelhos celulares conectados à internet, conversando com amigos, relacionando-se com interlocutores inéditos, postando vídeos no Youtube, configurando seus perfis no Facebook, e tantas outras formas e redes de interação, extrapolando os limites temporais e espaciais da escola. De acordo com os dados, mais de $90 \%$ dos jovens pesquisados se conectava ao Facebook na sala de aula, como se observa no depoimento abaixo:

Ontem eu achei que ia levar a maior bronca da professora... Ela deu um exercício pra fazer na sala, eu comecei a pesquisa sobre algumas questões na internet. Quanto ela notou que eu tava usando o meu celular, ela veio pediu pra eu desligar, aí eu mostrei que era coisa do exercício, aí ela disse: 'tá bom; mas você sabe que é proibido usar celular na sala. Cuidado pra não ter problema com a coordenação' (Talita, diário de campo, 25 set. 2012, escola particular).

A intensidade dessas trocas virtuais se diferencia conforme o dia, a aula e as atividades escolares. Em semana de prova e de matéria nova, o uso é menos intenso. Por outro lado, nos momentos de fazer exercícios e/ou atividades em sala, o uso midiático se intensifica. Há uma diferença também conforme as aulas e as relações com os professores. Se há um gosto ou preferência pelo conteúdo da matéria, a relação com os dispositivos midiáticos fica menos intensa ou ocorre objetivando tirar dúvidas da matéria e/ou do exercício proposto pelo professor. Observamos que a prática mais cotidiana de passar resumo escrito no quadro chegou em alguns momentos a ocupar mais de $70 \%$ da duração das aulas, com o agravante de que, em algumas dessas aulas, os professores nem sequer lançaram o olhar sobre os sujeitos ali presentes. A recíproca também foi constatada: nessas mesmas ocasiões, os estudantes ficavam mais envolvidos com seus celulares e aparelhos digitais; se ocupavam com leituras e com outros trabalhos escolares, conversas com o colega ao lado ou cochilavam. Outros fotografavam o resumo do quadro com seus celulares e o disponibilizavam rapidamente no Facebook, no espaço de grupo que os próprios alunos criaram para interagir em rede. A tensão maior em sala de aula se mostra, principalmente, na tentativa dos alunos de quebrar o ritmo linearizado do tempo escolar a partir de suas conexões online: estão ali em tempo real, enviando mensagens, informando a colegas não presentes sobre o que se passa em sala, postando atividades escolares no Facebook.

\section{Ampliação dos Processos de Sociabilidade}

Nos outros ambientes escolares por onde os alunos circulavam (quadras, corredores, biblioteca, laboratórios), as conexões midiáticas se repetiam, intensificando as interações on-line entre os alunos. Eles formavam grupos em torno de jogos, assistiam a vídeos, conversavam por mensagens e atualizavam juntos as suas redes sociais. Na escola particular, constatou-se a existência de um grupo de alunos, entre jovens do primeiro e do segundo ano, com presença e conexão assíduas 
neste espaço, ao longo de todo o ano letivo. Estes se reuniam na biblioteca para jogar online: uma atividade desenvolvida com bastante entusiasmo. Afinal, a biblioteca é o espaço com melhor potência de sinal wireless (rede sem fio) em toda a escola. Já na Escola Francisco, percebemos a pouca presença dos jovens alunos da sala $2 \mathrm{H}$ no ambiente da biblioteca - frequência que aumentava quando a professora de Literatura indicava o próximo livro a ser lido, como exercício da disciplina. Um dos jovens desta classe disse ter usado apenas uma vez os computadores da biblioteca para entrar na internet: "Quando vou a biblioteca é só pra entrar na internet” (Mateus, escola pública, 2012). No entanto, não se percebeu nenhuma relação mais intensa entre a mídia e a escola.

No espaço da quadra, na escola particular, quando o sinal soava, indicando o recreio, havia toda uma movimentação dos alunos para guardarem o material escolar e tomarem em mãos seus aparelhos digitais. Os alunos do Ensino Médio se misturavam com outros alunos no bloco do Ensino Fundamental, onde se situava uma das quadras e que era o lugar da maior parte dos encontros escolares entre os alunos do Carmem. Grande quantidade de alunos se espalhava pela quadra e pátio da escola. Muitos se posicionavam nas filas da cantina, outros conversavam e alguns jogavam futebol. Enquanto muitos riam, uns poucos arriscavam namorar, algo proibido na escola. Neste cenário, o uso de aparelhos eletrônicos/digitais se intensificava: jogos, músicas, vídeo, ligações. Além dos iphones, ipods e celulares, via-se os tablets, notebooks e outros variados aparelhos. A maior parte dos diálogos era mediada pelas tecnologias: conversavam com namorados e família pelo celular, riam juntos de tirinhas de humor partilhadas no Facebook, montavam grupos de jogos etc. Efetivamente, na maior parte das vezes, a sociabilidade dos jovens na escola se fazia pelo vínculo deles com as mídias, através dos jogos (games) e redes sociais, dos sites de entretenimento, de vídeos e filmes.

Na escola pública, essas cenas também se repetiam. Havia jovens com seus aparelhos, com seus games e suas trocas midiáticas na quadra escolar. Porém, nessa escola o recreio era um momento valorizado para curtir músicas. Assim, os alunos do Francisco ficavam na quadra conversando, dançando, ouvindo música e também fazendo suas trocas midiáticas, falando ao celular e jogando.

O recreio se transformava em uma feira tecnológica nas duas escolas: aparelhos de todos os tipos, modelos, tamanhos e marcas. No entanto, notou-se diferenças na posse e nas formas de uso midiáticos entre os alunos das duas escolas. Na escola particular, a quantidade de jovens acessando redes sociais, jogando, partilhando sites da internet foi visivelmente maior. Primeiramente, pelo fato de os alunos da escola particular terem acesso à rede sem fio da escola, bem como conexão com internet através de seus próprios celulares. Outra diferença estava no tipo de aparelho. Na escola particular, a variedade de aparelhos que se notava no recreio era muito mais ampla, principalmente no que 
se referia ao iphone e ipod, aparelhos muito raros entre os jovens das camadas populares. Por sua vez, o papel que a mídia desempenha na sociabilidade juvenil nos espaços escolares não se alterou significativamente para os dois contextos pesquisados. Na sala de aula o uso midiático era mais tensionado do que na quadra, no pátio, nos corredores e na bibliotecal.

Podemos dizer, assim, que as interações virtuais dos jovens-estudantes se prolongavam nos espaços escolares, fazendo com que o midiático se tornasse um efetivo elemento em suas interações escolares e na constituição de suas identidades de jovens-alunos. Porém, esses modos de ser jovem-aluno entravam em conflitos com o papel naturalizado de aluno que se produz no interior da instituição escolar. É preciso destacar que a rejeição dos jovens em relação ao ofício naturalizado de aluno dizia respeito ao fato de que a condição juvenil ser invisível nesse ofício. No entanto, os jovens não deixavam de levar para suas redes elementos desse ofício, tais como: postagens de datas de trabalhos, chamadas para exercícios, entre outros.

Esses dados da pesquisa confirmam a observação feita por Baccega (2002), segundo a qual estamos diante de uma geração de alunos que aprendem novos idiomas e formas de se relacionar com as tecnologias e com outros sujeitos, manifestando novas apreensões e usos da cultura escrita (preferem escrever ao computador que no papel, criam códigos alternativos para o vocabulário, transferem parcialmente a sala de aula para o espaço on-line). Ainda para tal autora, o desafio da escola não está apenas em usar adequadamente as mídias como ferramentas para o ensino-aprendizagem, mas em compreender os modos de ser jovem-aluno nesses contextos: "A escola precisa aprender a trabalhar as novas sensibilidades dos alunos; trata-se de outra maneira de ser e de ler, de sentir e apropriar-se do mundo, com relação à qual a escola não pode se omitir" (Baccega, 2002, p. 6). Portanto, a cultura midiática não pode ser ignorada e/ou relativizada como espaço de educação e de socialização na sociedade atual, mesmo que o processo de midiatização possa e/ou deva ser questionado na amplitude de inclusões e exclusões que aí se englobam.

\section{Tecendo Fios: entre o Facebook, turmas escolares e o ser jovem-aluno}

As redes sociais se apresentam como a ambiência mais expressiva e mais abrangente das relações midiatizadas dos jovens-alunos pesquisados. Trabalhamos com o conceito de redes sociais de Raquel Recuero (2008), que caracteriza as redes sociais na internet como agrupamentos complexos, instituídos por interações sociais apoiadas em tecnologias digitais de comunicação. Essas redes se configurariam por aspectos individuais, coletivos e tecnológicos dos agrupamentos humanos na internet. A partir delas, mudam-se as formas de organização da vida cotidiana, as construções identitárias dos sujeitos e suas conversações

290 Educação \& Realidade, Porto Alegre, v. 41, n. 1, p. 279-302, jan./mar. 2016. 
e mobilizações sociopolíticas. A autora ainda define rede social como um conjunto de dois elementos: atores (pessoas, instituição ou grupos) e suas conexões (interações ou laços sociais).

$\mathrm{O}$ fato de o site de rede social Facebook ser o preferido pelos jovens pesquisados, articulando entre eles processos de socialização, de sociabilidade e de escolarização, levou-nos a tomá-lo como espaço de observação da interação entre a experiência juvenil dos sujeitos pesquisados e suas condições de alunos.

Dos vários envolvimentos deles com esta rede, selecionamos as experiências virtualizadas/interacionais de suas três turmas escolares no Facebook. Analisamos como, via redes sociais, o processo de midiatização afeta a vida estudantil dos jovens pesquisados.

\section{Fios e Vínculos Constituidores das Relações Juvenis no Facebook}

Para além de seu objetivo inicial de criar uma rede de contatos entre alunos secundaristas estadunidenses, o Facebook foi agregando, junto a essas experiências escolarizadas, novas dinâmicas e interesses juvenis, agenciados, de um lado, pelos gestores da rede e, de outro, pelos jovens-alunos usuários. Assim, o Facebook transformou-se numa ambiência de vínculos variados para os jovens secundaristas. Destes, sobressaem-se, entre os jovens pesquisados, três tipos de vínculos assim categorizados: afetivos-relacionais, de sociabilidade e pedagógicos escolares.

Os vínculos afetivos-relacionais, informaram-nos sobre as relações juvenis, sobre seus contatos e sobre seus modos de estar com outras pessoas (amigos, familiares, namorados, etc.). Essas trocas juvenis em rede afetavam e/ou eram afetadas por relações interpessoais significativas, por trocas comunicativas, pela disposição e/ou gosto de compartilhar algo com os amigos da rede. Os jovens disseram acessar o Facebook para conversar com outros jovens, enviar mensagens positivas ou conselhos, namorar, colocar ideias, compartilhar frases religiosas, etc.

Os vínculos de sociabilidade informaram-nos sobre como as relações juvenis construídas no Facebook abriam espaços para momentos de sociabilidades vividos de forma on-line ou não. Segundo os jovens: No Face, a gente cria os eventos de festas, de encontros, o churrasco da turma da escola. O Facebook era também acessado como um lugar para encontrar outros jovens, para se relacionar com grupos de interesses e ampliar as amizades.

Enfim, destacaram-se os vínculos pedagógicos e escolares. Para além de vários processos de aprendizagem colaborativos não escolares, os jovens vivenciavam a experiência da turma escolar no Facebook, que se mostrou como um espaço de aprendizagem, de interações entre estudantes, de troca de informações sobre a escola, bem como um meio de administrar parte das tarefas e vivências escolares. Como disse a 
jovem-aluna: "Eu sinto que a nossa sala no Facebook é a nossa sala de verdade, porque lá a gente pode ser uma turma de verdade, colaborar ali um com o outro" (Lorena, Escola particular, 2012).

Os jovens estudantes faziam uso das redes sociais também para desenvolver seus processos de escolarização ao levar elementos de sua vida escolar ao Facebook. De um lado, este trazer a escola para a rede se efetuava acessando elementos escolarizados, tais como aprender conteúdos, estudar, pesquisar e relacionar-se com os demais sujeitos escolarizados. De outro lado, os jovens contemplavam elementos formalmente menos escolarizados, tais como a sociabilidade com os colegas e professores, os eventos extraclasse, a formação dos grupos e as festas.

Havia um processo de virtualização das turmas escolares no $\mathrm{Fa}$ cebook. Por meio de interações virtuais, os alunos compartilhavam atividades gerais vividas na escola, principalmente, na sala de aula, tais como lições, trabalhos, calendários, provas, materiais didáticos e pedagógicos, fotos do quadro escanner do caderno e/ou do livro didático. Além disso, eles vivenciavam outra temporalidade escolar, compartilhavam eventos, marcavam encontros, humorizavam situações escolares, brigavam, praticavam bullying, colaboravam uns com os outros em seus estudos e atividades, criticavam e elogiavam professores, promoviam reivindicações e se mobilizavam contra regras e outras situações escolares. Assim, nota-se no debate do grupo abaixo da turma Avenida $2 \mathrm{ml}$ :

Entrevistadora: Por que vocês criaram a turma $2 \mathrm{ml}$ no Facebook?

Mara: É uma estratégia dos alunos de hoje, porque todo mundo tá no $\mathrm{Fa}$ cebook. Facilita a vida do aluno. Você pergunta o que vai cair na prova, o que tem pra manhã, matérias, as respostas são sempre imediatas.

Vinícius: Posta lá também alguma coisa para descontrair.

Mara: Não aceitamos professor no grupo, porque a gente pensou assim mais como um espaço da turma, uma sala assim mais com a nossa cara, mais de jovem, onde a gente fala sério, mas também poder fazer ali zoação, pode brincar. Então a gente queria assim que fosse um espaço mais da gente, mais do aluno e não da escola.

Carla: A gente usa esse espaço o máximo para ajudar a turma no que for possível em termos das coisas da escola (Grupo de Discussão Avenida 2m1, escola particular, 2012).

O debate acima é um indicador de que o sentido da turma escolar virtual era bastante amplo envolvendo relações pedagógicas, de sociabilidade e amizade, colaborativas e de enfrentamento das regras escolares. A sala ou turma virtual era uma forma e/ou um espaço de relações mais coletivas do corpo discente diante do que lhes era proposto pela escola. Muitas vezes, esse espaço on-line era utilizado para a tomada de decisões que envolviam questões e interesses particulares da turma, como: mudança de calendário de prova, boicotes a aulas e provas, entre outros. Todos os jovens pesquisados citaram como ganho dessa turma virtual a autonomia como alunos, sentindo-se livres para tirar dúvidas, comentar sobre o professor, sobre a escola, colaborar e até mesmo posicionar-se contra certas decisões da escola. 
As formas de interação dos jovens nessas turmas on-line foram identificadas em seções, assim classificadas: a) Seções de informações gerais, com perguntas e postagens em torno das atividades, vistos no caderno e para-casa, trabalhos, calendários, provas, recuperação, matérias e aulas; b) Sessões pedagógicas, com dinâmicas para execução de trabalhos e eventos escolares, estudos em grupo e tópicos de aprendizagem colaborativa (tirar dúvidas de matéria, contribuir com um trabalho, oferecer ajudas); c) Seções de sociabilidade, com organização e/ou participação em eventos escolares, de festa, assistência em grupo de vídeos de humor e brincadeiras; d) Seções materiais, com a divulgação de videoaula e resumos literários, acessando sites de pesquisa, páginas de disciplinas e blogs temáticos; e) Seções de debates, acordados em turma, com conversas sobre regras escolares, administração grupal de problemas vividos pela turma, com professores e com a direção; f) Seções de intrigas: brigas, dificuldades relacionais e casos de bullying.

Apesar de as seções serem comuns às três turmas, entre elas havia elementos e campos interacionais específicos na dinâmica on-line dessas turmas. Estas se diferenciavam em termos de facilidade de acesso à mídia por parte dos alunos, de expressões grupais, de trocas estabelecidas e de relações afetivas ali administradas, conforme os objetivos da turma, as decisões tomadas, os temas linkados, os materiais compartilhados, a relação prevista com as regras escolares e com os próprios professores.

\section{A Turma da Escola Pública no Facebook}

Quanto à turma $2 \mathrm{H}$ da escola pública, um elemento diferenciador desta em comparação às turmas da escola particular era a participação dos alunos neste espaço virtual. Notamos certo desequilíbrio das participações entre os alunos: um grupo em específico era o que conduzia a maior parte das interações, seja administrando perguntas e respostas, seja propondo questões e debates. Alguns alunos liam as informações, mas não interagiam com a turma. É de se notar que esses mesmos alunos também se encontravam mais invisíveis no cotidiano off-line da sala de aula. Procurando dados para tal explicação, chegamos a três tipos de argumentos: baixo acesso à internet, escassez de tempo devido ao trabalho e problemas de relacionamento pessoal com os colegas. Parte dos jovens da turma $2 \mathrm{H}$ não tinha internet banda larga em casa, $\mathrm{o}$ que dificultava o acesso à turma no Facebook. Tal dificuldade devia-se também ao fato de a turma ser composta por jovens trabalhadores que tinham um tempo menor de acesso ao mundo on-line e outros alunos não se achavam motivados a tal participação devido às dificuldades relacionais com alguns colegas.

Observamos também que a "seção materiais" foi pouco explorada pela turma $2 \mathrm{H}$. Durante o ano de 2012, foram postadas apenas seis videoaulas, alguns links de sites e um resumo literário. Assim o aluno Leandro, da escola pública, avaliava a participação de sua turma no Facebook:

Educação \& Realidade, Porto Alegre, v. 41, n. 1, p. 279-302, jan./mar. 2016. 
Nossa turma 2H está muito tímida para usar os recursos que o Face oferece; a gente não partilha as videoaulas, não linka ali outras redes sociais; o espaço tá muito só nas informações mais gerais das atividades; ainda temos que melhorar muito (Leandro, Entrevista, 2012, escola pública).

As seções relações e aprendizagens colaborativas também eram pouco vivenciadas pela turma $2 \mathrm{H}$. Não se notou, como nas demais turmas, o hábito de marcar estudos em grupo e/ou tirar dúvidas sobre determinado conteúdo de forma coletiva. Observamos ainda tensões bem marcadas entre alunos individualmente, que afetavam suas relações na turma. Como se pode observar no trecho abaixo publicado na página dessa turma no Facebook:

Gabriel: Véi, aqui não é espaço para publicar essas coisas de governo... Hélio: Quem ñ q não curte, o pior analfabeto é o analfabeto político... Gabriel: melhor ser analfabeto q.....

Rafael: Calma gente, tá perdendo a classe...

Gabriel: "Ah véi, o cara fica tirando onda com a cara da gente".

Maria: Você é que começou Bi... a pessoa posta o que quiser é só você não curtir.

Gabriel: Tá bom, todo mundo posta o que quiser e o grupo perde o foco né.

Rafael: Apelou, perdeu, vão dormir pessoas, amanhã é outro dia.

(Fonte: Facebook, Turma 2H, escola pública, 2012).

Assim, algumas vezes, havia relações tensas em torno de opiniões, brincadeiras que levavam a discussões e até ofensas; aconteciam situações de bullying e indicações de tensões com professores. Estas também se faziam presentes nas turmas da escola particular, mas com índices menores de ocorrência.

A relação com o trabalho escolar era algo que movimentava as interações entre os alunos das três turmas no Facebook: os alunos combinavam montagem do trabalho em rede, discriminavam os conteúdos, faziam divisões de tarefas e organizavam encontros. Mas, no caso dos jovens da escola pública, uma prática muito comum (não verificada nas outras turmas) é a situação de venda de trabalhos escolares em rede. Isto se verificou no final dos trimestres letivos, quando se acumulavam trabalhos, provas e atividades. Os alunos trabalhadores eram os que viviam com mais dificuldades essa situação. Nesse caso, os alunos que tinham menos dificuldades em relação aos conteúdos, que estavam em dia com as tarefas escolares e não necessitavam fazer provas de recuperação, ficavam à disposição e/ou ofereciam aos colegas o serviço de confecção dos trabalhos. Cada trabalho tinha um preço conforme a exigência e o tamanho, como demonstra o fragmento abaixo, retirado do mural da turma $2 \mathrm{H}$ no Facebook: 
Figura 1 - Postagem do Mural da Turma 2H no Facebook

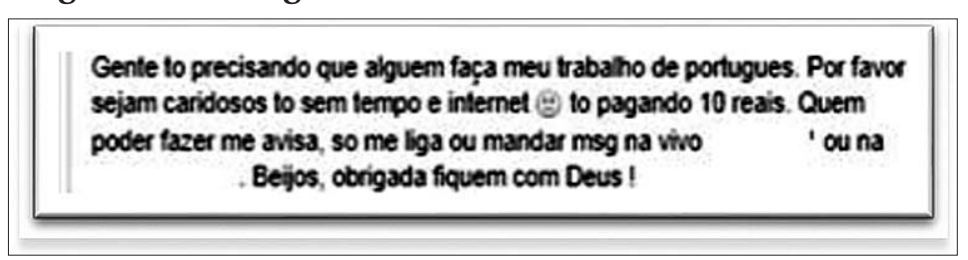

Fonte: Facebook, Turma 2H, escola pública, 20127.

\section{As Turmas da Escola Particular no Facebook}

Quanto à Turma $2 m 2$ da escola particular, observou-se um equilíbrio maior na administração das seções. Essa turma era a que mais investia na sessão colaboração e seção material. Na seção colaboração, eles contribuíam com os colegas postando vídeos em dia de prova, indicando sites e organizando grupos de estudos. Abaixo, indicamos um pequeno fragmento de um desses grupos de estudo realizado via skype:

Marlon: Oiiiiiii

Pedro: Oiiiii Galera

Nati: Oi gente, já vou avisando, não sei nada de Revolução Russa

Talita: Calma Nati, eu peguei uma videoaula no Descomplica e estou com tudo na cabeça.

Marlon: A gente vai falando e pintando as dúvidas a gente tira?

Pedro: Beleza! Começa aí Talita.

Talita: Tá bom! O que eu estudei é que a Rússia estava vivendo uma situação econômica bem complicada. A situação dos trabalhadores era precária.

Nati: Ah, gente, isso eu sei. O mais difícil é entender aquele treco de Bolchevismo... (Grupo de Discussão 2m2, escola particular, 2012).

Durante $\mathrm{o}$ ano de 2012, os alunos da turma $2 \mathrm{~m} 2$ postaram mais de 80 videoaulas das disciplinas, 15 resumos de literatura, inúmeros sites com aulas de conhecimentos gerais e muitas dicas para estudo. Uma ação comum dessa turma foi a organização on-line de boicotes às aulas e/ou reações contra decisões e regras escolares, a favor de ações que lhes eram convenientes, como faltar às aulas, combinar sobre exercícios, reivindicar alguma necessidade da turma junto à coordenação pedagógica e fazer greve contra o calendário de provas.

Houve um fato que mudou a relação dos alunos na turma $2 \mathrm{~m} 2 \mathrm{e}$ comprometeu temporariamente as interações no espaço da sala virtual: a entrada do professor de inglês no grupo. A adição desse professor foi uma decisão tomada individualmente pelo aluno administrador do grupo. A turma tomou ciência da situação a partir do aviso abaixo, postado na página da turma: 
Figura 2 - Facebook, Turma 2m2, Escola Particular

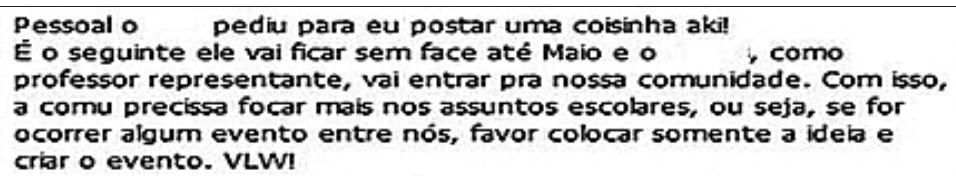

Fonte: Facebook, Turma 2m2, escola pública, 2012.

A notícia provocou descontentamentos na turma, causando a briga direta com o aluno administrador. Mesmo assim, o professor passou a fazer parte do grupo. Ao longo de sua participação, ocorreram divergências entre ele e os alunos, pois o professor levava algumas situações vividas no grupo virtual para a sala de aula, provocando tensões entre ele, o aluno administrador e parte expressiva da turma. Tendo passado certo tempo no grupo, o professor se retirou depois de cancelar o seu perfil no Facebook. Esse episódio foi comentado no grupo de discussão da turma $2 \mathrm{~m} 2$ :

Ângelo: Olha, eu acho que uma marca muito grande da nossa turma é a troca no grupo do Face. É um espaço dos alunos, mas o professor de inglês só fica só vigiando a gente, eu não to gostando da presença dele lá não, ele fica inibindo a gente.

Cristina: Nossa ele fica metendo o olho em tudo, fica intimidando..

Igor: Ele fica comentando as coisas que a gente posta lá, fica falando de tudo. Teve um dia que o pessoal ficou falando que algumas aulas estavam muito chatas. Aí o professor achou ruim desse comentário, ficou falando pra gente estudar, em vez de ficar conversando fiado. Igual outro dia: o professor chegou em sala de aula e ficou brigando com a Talita. Ele falou: da próxima vez que você postar no grupo coisas no horário da aula, vai ser uma conversa entre você, eu e a coordenadora.

Entrevistadora: Mas por que vocês aceitaram ele no grupo?

Ângelo: Não somos nós; foi o Fabrício sem falar com a turma. É porque o professor é padrinho da turma e o Fabrício é o administrador do grupo, aí ele colocou.

(Grupo de Discussão 2m2, escola particular, 2012).

Por fim, temos as interações estabelecidas na turma Avenida $2 \mathrm{~m} 1$. Essa turma manifestou relações muito parecidas às do grupo $2 \mathrm{~m} 2$. A maior diferença está na Seção Sociabilidade, pois os alunos dessa turma usavam constantemente o espaço da sala de aula virtual para administrar práticas de entretenimento como festas e usavam muito o recurso do humor e vídeos de piadas em suas comunicações. As brincadeiras, em alguns momentos, também causavam situações de constrangimento para alguns alunos. Havia também, em contraste com as demais turmas, a prática de divulgação de temáticas voltadas às questões políticas, divulgação de projetos sociais e também um espaço maior de liberdade para os alunos postarem coisas particulares no grupo.

Apesar dessas diferenças, nas experiências on-line das turmas escolares, notamos quatro formas centrais de interação comuns a elas, que articulavam as seções indicadas anteriormente. 


\section{Formas de Interações nas Turmas Virtuais}

A primeira forma de interação caracterizou-se como ordinária por ser a mais recorrente. O catalisador da interação nesse caso eram as perguntas sobre atividades escolares, como provas, datas, trabalhos, exercícios, lembretes de para-casa, postagem de resumos, fotos tiradas da matéria no quadro, calendários, horários de aula e outros. Vejamos o fragmento abaixo retirado do mural do Facebook da turma $2 \mathrm{H}$ :

Trabalho de geografia pros navegantes: Grupo é formado de 4 alunos deverão fazer uma pesquisa sobre 'Internacionalização econômica da globalização'. O grupo deverá associar a atuação do capital financeiro e das grandes corporações transnacionais com o processo da internacionalização da economia (Facebook, Turma 2H, 2012).

A segunda forma de interação caracteriza-se como cooperativa el ou colaborativa. Os alunos interagiam entre si ao resolver dúvidas sobre os conteúdos que não foram bem entendidos, colocavam-se à disposição dos colegas para ajudar em trabalhos e matérias de provas, uniam-se para resolver alguma questão pendente na turma e postavam videoaulas, resumos e análise de obras literárias. Como no trecho abaixo:

Paula: Alguém sabe 1 boa definição de manto?

Márcia: só precisa saber que ele produz o exoesqueleto e que a pérola é retirada dele

Rogério: Manto é uma camada de tecido q recobre a massa visceral e produz o exoesqueleto isso isso isso. Achei esse site: Anelídeos: a digestão, excreção e reprodução das minhocas I Frases e ditados populares, raças de cães (Facebook, Turma Avenida 2ml, escola particular, 2012).

Nesse tipo de interação, os jovens postavam declarações de amizades, tirinhas de autoajuda e frases para reflexão, reforçando suas proximidades. Esta se intensificava em momentos como início do ano, férias, final de ano letivo, como postado pelo jovem Otávio da turma $2 \mathrm{H}$ : "Galera, o Ano está acabando e só tenho a agradecer a turma $2 \mathrm{H}$, a vcs da turma por terem me recebido bem e por terem feito parte da minha vida nesse ano" (Otávio, Escola Pública, 2012).

A terceira interação se caracteriza como vínculos de sociabilidade: os alunos organizavam festas, passeios, idas a shows e cinema, idas a parques, participação em eventos da cidade, faziam brincadeiras com os colegas e recordavam aniversários, além de postar vídeos e fotos engraçadas da turma. Como ilustra o seguinte trecho do aluno Mateus, da mesma turma: "Gente parque ecológico no sábado ou no domingo? Vote aí quem quer ir no sábado ou no domingo!” (Facebook-Turma 2H, escola pública).

Nesse tipo de interação, encontrava-se o humor sobre as aulas e conversas relacionadas ao desempenho e postura de professores, entre outros assuntos. O recurso a posts irônicos era muito utilizado, como o post abaixo:

Educação \& Realidade, Porto Alegre, v. 41, n. 1, p. 279-302, jan./mar. 2016. 
Figura 3 - Muito Tédio

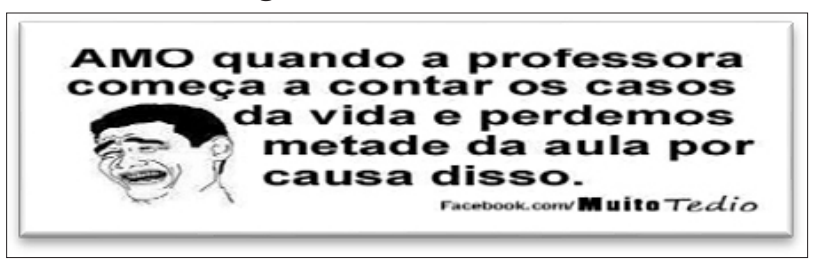

Fonte: Página Muito Tédio do Facebook ${ }^{8}$.

Esse tipo de interação se fazia presente entre todas as turmas. As tirinhas sobre resultados escolares, sobre o papel do aluno são encontradas em sua maior parte entre os alunos da turma $2 \mathrm{H}$ da escola pública. Quanto às falas sobre os professores, percebeu-se maior tensão entre os alunos da $2 \mathrm{H}$, da escola pública, que os demais. Parte dos alunos da escola pública reclamava do tratamento recebido dos professores em sala de aula, do distanciamento afetivo entre ambos e da forma como suas atividades escolares eram corrigidas pelos docentes.

Mesmo que, em certos momentos, essa tensão com o professor aparecesse na fala dos alunos da escola privada, ela era menos presente em suas interações on-line no grupo virtual. Os comentários voltados para os professores da escola privada tendiam a ser mais positivos. Os alunos comentavam fotos dos professores, lamentavam a perda de alguns e festejam a volta de outros.

A quarta forma de interação caracterizava-se como extraordinária. Nesse caso, os alunos se posicionavam sobre algumas regras escolares, sobre decisões da coordenação ou direção e faziam comentários sobre os professores. É dita extraordinária por dar-se mais raramente, mais notada entre os jovens do grupo virtual Avenida $2 \mathrm{ml}$, como no post a seguir:

Luiz: To irado é com essa coisa de q a gente vai fazer prova toda segunda. Será q o diretor vai ficar de plantão na escola nos finais de semana?

Mirtes: Pois é, lá se foram embora nossos finais de semana.

(Facebook, Turma Avenida 2ml, escola pública, 2012).

É interessante percebermos que os jovens opinavam sobre as regras escolares e desejavam participar das decisões e, assim, o espaço virtual se apresentava como possibilidade colaborativa e política.

\section{Considerações Finais}

Os jovens são os sujeitos que se veem mais cotidianamente afetados pela midiatização em seus mapas de referências culturais e identitários. Eles navegam em rotas que se cruzam, entre espaços midiáticos e escolares, promovendo trocas e interações (extensas e intensas, de inclusão e/ou exclusão) entre virtualidades e realidades cotidianas, identificando-se com diferentes papéis sociais e grupos de relaciona- 
mentos, como as inscrições de perfis de suas turmas escolares no $\mathrm{Fa}$ cebook. De seu lugar experiencial, o virtual e o real se aproximam nos sujeitos jovens como dois polos das mesmas interações. Porém, a experiência de ser jovem e ser aluno na sociedade midiatizada se diversifica conforme a situação juvenil e contexto social em análise, com diferenças significativas entre os estudantes da escola particular e da escola pública. Notamos, por exemplo, que os estudantes da escola particular se relacionavam de forma mais assídua com seus colegas e professores no espaço on-line e utilizavam mais intensamente a materialidade midiática em suas aprendizagens escolares: sites, blogs temáticos, páginas de disciplinas. Além disso, eles expressavam maiores tensões entre suas experiências midiáticas e a instituição escolar com suas rotinas, atividades e sujeitos.

Na perspectiva dos jovens-alunos pesquisados, destacamos que, mais que oferta de aparelhos inovadores e funcionais, a mídia tem proporcionado um espaço ou ambiente a que os jovens acessam para expressar-se e encontrar-se, estimulados pela quantidade e diversidade das opções oferecidas pelas mídias disponíveis, especialmente de modo on-line. Assim, em grande medida, os jovens-alunos contemporâneos são sujeitos midiatizados, transitando nas mídias/redes sociais e no espaço escolar em habitual interatividade com seus pares, com a escola e seus atores. Mas é preciso atentar-se para o fato de que o valor da tecnologia, na experiência estudantil dos jovens pesquisados, não residia na eficiência dos aparatos, mas na relação que o fazer juvenil criava com as coisas e objetos, neste contexto midiatizado. Nesse sentido, há um processo de mútua-afetação entre ser jovem e ser aluno nos ambientes on-line. Não percebemos neles grandes cisões entre ser jovem e ser aluno, mas um grande processo de tensão.

Outro elemento que nos chamou atenção foi o fato de que os alunos ao mesmo tempo que rejeitavam o ofício de aluno na sala de aula o reproduziam no espaço on-line. O ofício naturalizado de aluno ocupava um espaço significativo nas relações dos jovens em suas turmas virtuais: postagem de fotos de matérias, recados e lembretes de exercícios, calendários, provas, trabalhos, busca por informações e materiais sobre conteúdos das disciplinas. Notaram-se algumas repetições naturalizadas sobre responsabilidades com as tarefas escolares, a relação entre resultados escolares e comportamentos em sala de aula e entre aprendizagens e méritos. Uma parte significativa dos jovens pesquisados ocupava tal espaço virtual com o único objetivo de ter acesso às atividades escolares, nesse caso revelando uma apropriação limitada e instrumental dele. Mas, esse reforço ou reprodução do trabalho de aluno em rede, alertou-nos para outros elementos que atravessavam tal ofício e que são marcas próprias dos jovens-alunos, hoje midiatizados: o tempo do fazer escolar não linear, a maior prática da coletivização do trabalho escolar, a intensificação das trocas de aprendizagens, a diversificação das formas de acesso aos conteúdos escolares. 
Assim, foi possível perceber uma produção complexa de vínculos entre os jovens estudantes e o ensino médio, que desafiavam tempos e espaços institucionalizados e, para além da dimensão cognitiva, envolviam aspectos sociais, políticos, identitários, da sociabilidade e interacionais. Porém, de forma geral, os jovens pesquisados nos indicaram que essa nova ambiência comunicativa inaugura novas formas de produzir e processar saberes, favorece novas formas de interação e remodela os modos de ser jovem-aluno na contemporaneidade, o que desafia nossa compreensão escolar do processo de interação entre jovens-alunos e o contexto midiático contemporâneo.

Recebido em 20 de maio de 2015 Aprovado em 04 de dezembro de 2015

\section{Notas}

10 termo "afetação" vem sendo usado pelos autores da comunicação como contraponto a outros termos como "efeito" e "impacto" utilizados pelo paradigma informacional. "Afetação", utilizado nas abordagens que adotam o paradigma relacional da comunicação, refere-se uma perspectiva aberta e processual da relação entre dispositivos comunicacionais e usuários.

2 Estes são nomes fictícios em vista de preservar a identidade de cada escola pesquisada.

3 Este questionário foi aplicado logo no início da pesquisa de campo, sendo respondido por todos os jovens do ensino médio das escolas pesquisadas. No Instituto Carmem Pereira, participaram desse primeiro momento da pesquisa 189 alunos; e, na Escola Estadual Francisco do Amaral, 144 jovens. Tendo em consideração os objetivos e limites desse artigo, não é possível apresentar todos os dados referentes a esse instrumento de pesquisa.

4 As turmas foram indicadas pelas próprias escolas. No caso do Instituto Carmem Pereira, trabalhou-se com a observação em duas turmas devido a uma exigência feita pela própria escola. Segundo a coordenadora pedagógica, é uma prática da escola não excluir turmas da mesma série em qualquer tipo de trabalho proposto.

5 Como indicado anteriormente, os alunos criaram turmas no site de rede social Facebook que funcionavam autonomamente, sem o controle dos docentes e gestores das instituições, e se constituía em um dispositivo de mobilização, organização e interação entre eles. A particularidade da observação do site de rede social Facebook se deveu ao fato de que esta rede social ser a mais acessada, naquele momento, pelos jovens pesquisados. Do total dos 58 jovens-alunos (entrevistados individualmente e que compuseram os grupos de discussão), apenas dois não tinham uma conta no Facebook. Além disso, é relevante o tempo de conexão nessa rede social, que variava entre 4 a 14 horas diárias.

6 As principais diferenças entre AC e AD é o modo de acesso ao objeto. A interpretação da AC pode ser tanto quantitativa quanto qualitativa, enquanto que na $\mathrm{AD}$ a interpretação será somente qualitativa. AC trabalha tradicionalmente com materiais escritos. Existem dois tipos de textos que podem ser trabalhados pela AC: os textos produzidos em pesquisa, através das transcrições de entrevistas e de protocolos de observação, e os textos já existentes, produzidos para outros

300 Educação \& Realidade, Porto Alegre, v. 41, n. 1, p. 279-302, jan./mar. 2016. 
fins. Na AD, existe o corpus de arquivo e empírico. Quando se analisa em AD, o material já existe (como documentos, legislação, pronunciamentos em jornal, livros e outros) e refere-se ao corpus de arquivo; se o material é construído especialmente para a pesquisa, como, por exemplo, através de entrevista, refere-se ao corpus empírico, experimental. A principal diferença entre as duas formas de análise é que a $\mathrm{AD}$ trabalha com o sentido e não com o conteúdo; já a $\mathrm{AC}$ trabalha com o conteúdo, ou seja, com a materialidade linguística através das condições empíricas do texto, estabelecendo categorias para a sua interpretação. Enquanto a AD busca os efeitos de sentido, a AC fixa no conteúdo do texto, sem fazer relações além deste. O pesquisador, ao utilizar a $\mathrm{AD}$, fará uma leitura do texto enfocando a posição discursiva do sujeito, legitimada pela união do social, da história e da ideologia, produzindo sentidos. Na utilização da AC o que se visa no texto é justamente uma série de significações que o codificador detecta por meio dos indicadores que estão ligados.

7 Para manter a confidencialidade dos jovens não foram inseridas as fontes dos trechos extraídos das páginas das turmas no facebook.

8 Disponível em: <https://www.facebook.com/muitotedio?fref=ts>.

\section{Referências}

ANDRÉ, Marli. Estudo de Caso em Pesquisa e Avaliação Educacional. Brasília: Liber Livro, 2008.

BACCEGA, Maria Aparecida. Televisão e Escola: aproximações e distanciamentos. In: CONGRESSO BRASILEIRO DE CIÊNCIAS DA COMUNICAÇÃO, 25, 2002, Salvador. Anais... Salvador: 2002. Disponível em: <http://www.intercom. org.br/papers/nacionais/2002/Congresso2002_Anais/2002_NP11BACCEGA. pdf $>$. Acesso em: 6 out. 2012.

BENVENISTE, Émile. Problèmes de Linguistique Générale. Paris: Gallimard, 1974.

BRAGA, José Luiz. Midiatização como Processo Interacional de Referência. In: MÉDOLA, Ana Sílvia; ARAÚJO, Denize Correa; BRUNO, Fernanda (Org.). Imagem, Visibilidade e Cultura Midiática. Porto Alegre: Sulina, 2007. P. 141-167.

BRASIL. Lei no 9.394/1996, de 23 de dezembro de 1996. Estabelece as Diretrizes e Bases da Educação Nacional. Diário Oficial da União, Brasília, 23 dez. 1996. P. 27833.

CASTELLS, Manuel. Inovação, Liberdade e Poder na Era da Informação. In: MORAES, Denis (Org.). Sociedade Midiatizada. Rio de Janeiro: Mauad, 2008. P. 225-231.

DAYRELL, Juarez. Juventude, Grupos de Estilo e Identidade. Educação em Revista, Belo Horizonte, n. 30, p. 25-39, dez. 1999. Disponível em: <http://educa. fcc.org.br/pdf/edur/n30/n30a04.pdf>. Acesso em: 07 dez. 2013.

DAYRELL, Juarez. A Escola Faz as Juventudes? Reflexões em torno da socialização juvenil. Educação e Sociedade, Campinas, v. 28, n. 100, p. 1105-1128, 2007. DUBET, François. Sociologia da Experiência. Lisboa: Instituto Piaget, 1994.

ESCOLA eSTADUAL FRANCISCO DO AMARAL. Projeto Político-Pedagógico 2011. Belo Horizonte: Escola Estadual Francisco do Amaral, 2011.

INSTITUTO CARMEM PEREIRA. Projeto Político-Pedagógico Pastoral. Belo Horizonte: Instituto Carmem Pereira, 2011. 
LEVI, Giovanni; SCHMITT, Jean-Claude. História dos Jovens 2: a época contemporânea. São Paulo: Companhia das Letras, 1996.

MARTUCCELLI, Danilo; SINGLYS, Francois. Sociologies de L'Individu. Paris: Armand Colin, 2012.

MELUCCI, Alberto. O Jogo do Eu: a mudança de si em uma sociedade global. São Leopoldo: Unisinos, 2004.

MELUCCI, Alberto. Por uma Sociologia Reflexiva: pesquisa qualitativa e cultura. Petrópolis: Vozes, 2005.

RECUERO, Raquel. Redes Sociais na Internet. Porto Alegre: Sulina, 2008.

SOUSA, Cirlene Cristina de. Juventude(s), Mídia e Escola: ser jovem e ser aluno face à midiatização das sociedades contemporâneas. 2014. 376 f. Tese (Doutorado em Educação) - Faculdade de Educação, Universidade Federal de Minas Gerais, Belo Horizonte, 2014. Disponível em: <http://www.bibliotecadigital.ufmg. br/dspace/handle/1843/BUOS-9TDJ7J>. Acesso em: 20 nov. 2014.

SPOSITO, Marília; SETTON, Maria. Como os Indivíduos se Tornam Indivíduos? Educação e Pesquisa, São Paulo, v. 39, n. 1, p. 247-267, jan./mar. 2013. Disponível em: <http://www.revistas.usp.br/ep/article/view/53054>. Acesso em: 23 out. 2014.

Cirlene Cristina de Sousa é doutora em Educação pelo Programa de Pós- Graduação em Educação da UFMG, Professora Formadora do Pacto Nacional pelo Ensino Médio e Pesquisadora do Observatório da Juventude da UFMG.

E-mail: cirlenesousa@yahoo.com.br

Geraldo Magela Pereira Leão é professor associado da Faculdade de Educação e do Programa de Pós-Graduação da Universidade Federal de Minas Gerais e pesquisador do Observatório da Juventude da UFMG.

E-mail: gleao2001@yahoo.com.br 